\title{
Langerhans cells in periodontal disease of HIV- and HIV+ patients undergoing highly active antiretroviral therapy
}

Takeshi Kato Segundo(a) Giovanna Ribeiro Souto(b) Ricardo Alves Mesquita ${ }^{(b)}$ Fernando Oliveira Costa ${ }^{(a)}$

(a) Department of Periodontology, Dental School, Federal University of Minas Gerais, Belo Horizonte, MG, Brazil.

(b) Department of Oral Surgery and Pathology, Dental School, Federal University of Minas Gerais, Belo Horizonte, MG, Brazil.
Corresponding author:

Takeshi Kato Segundo

Av. Brasil, 283/1108

CEP: $30140-001$

Belo Horizonte - MG - Brazil

E-mail takeshisegundo@hotmail.com

Received for publication on Dec 02, 2010 Accepted for publication on Feb 15, 2011

\begin{abstract}
The aim of this study was to assess and compare quantitatively the presence of S100+ Langerhans cells (LC) by immunochemistry techniques in $\mathrm{HIV}+$ and HIV- gingivitis and periodontitis subjects. Additionally, it aimed to evaluate the correlation among densities of these cells with CD4+ and CD8+ T cells, and viral load levels in HIV+ subjects, all using Highly Active Antiretroviral Therapy (HAART). The samples were allocated into four groups: 1) 15 subjects with moderate chronic periodontitis (MCP), HIV+; 2) 15 subjects with MCP, HIV-; 3) 10 subjects with gingivitis (G), HIV+; and 4) 10 subjects with G, HIV-. The S100+ cells were assessed in the pocket epithelium, gingival epithelium, and lamina propria. A statistically significant increase of total S100+ cells in $\mathrm{HIV}+$ periodontitis subjects was observed in relation to HIV- periodontitis subjects. No increase of $\mathrm{S} 100+$ cells with increased inflammation was observed. No statistically significant correlation among S100+ cells and blood levels of CD4, CD8, and viral load was observed. In conclusion, the use of HAART can aid in achieving viral loads, and it is suggested that it may prevent the destruction of the LC.
\end{abstract}

Descriptors: Langerhans Cells; Gingivitis; Periodontitis; HIV.

\section{Introduction}

Langerhans cells (LC) are the first cells of the immune system capable of uptaking, processing, and presenting foreign antigens to T-lymphocytes. ${ }^{1}$ Experimental studies have shown differences in the number of LC among patients with gingivitis, periodontitis, and clinically healthy gingiva. ${ }^{2,3}$ Although a larger number of cells was observed with increased inflammation, ${ }^{4,5}$ a low quantitative difference was observed between gingivitis and periodontitis. ${ }^{6}$

HIV infection is a modifier factor for periodontal disease, responsible for the depletion of CD4+ T lymphocytes, macrophages and LC. ${ }^{7,8}$ As a result of this infection, in HIV+ patients with periodontitis, LC were decreased as compared with HIV- subjects' ${ }^{9}$ moreover, the former showed a significant decrease in major histocompatibility complex class II (MHC-II) expression. ${ }^{10}$

Recent reports have not indicated a major severity of periodontal disease in HIV+ patients under treatment with antiretroviral agents. ${ }^{11,12}$ The antiretroviral treatment has also resulted in a significant reduction in mortality and morbidity. Nowadays, the combination of drugs is called 
highly active anti-retroviral therapy (HAART). ${ }^{8}$

Although a large part of LC immunologic activity in HIV- patients has been described, ${ }^{1}$ we have little knowledge about the distribution of these cells in inflamed periodontal tissue in HIV+ subjects using HAART. Strong evidence has shown that the introduction of HAART for the medical management of HIV+ subjects has resulted in a marked decrease in the severity of periodontal diseases in this population. ${ }^{8}$ However, the impact of this therapy on LC needs to be determined.

Thus, to gain a better understanding of the immune response in HIV+ subjects, we proposed this study: to assess and compare quantitatively S100+ LC in plaque-induced human gingivitis and periodontitis among both HIV- subjects and HIV+ subjects using HAART; also, to evaluate the correlation among densities of these cells with CD4+ and CD8+ $\mathrm{T}$ cells, and viral load levels in HIV+ subjects, all using HAART.

\section{Methodology}

This study was approved by the Committee of Bioethics in Research from the Federal University of Minas Gerais (COEP number 514/07).

LC are identified by their immune-reactivity against the S100 protein and the CD1a antigen; in the present study, the antibody anti-S100 protein was used to verify their presence in both the epithelium and lamina propria regions. ${ }^{13}$

The sample comprised $25 \mathrm{HIV}+$ and $25 \mathrm{HIV}-$ patients. The two groups presented both chronic moderate periodontitis (CMP) (15 HIV- with CMP and $15 \mathrm{HIV}+$ with $\mathrm{CMP}$ ) and gingivitis (G) (10 HIV- with G and 10 HIV+ with G). The patients ranged from 30 to 60 years of age and represented both genders. The periodontal conditions were defined according to the following criteria:

- Gingivitis: probing depth (PD) $<4 \mathrm{~mm}$, bleeding on probing $>25 \%$ sites present. ${ }^{14}$

- Chronic moderate periodontitis: considered together with the following criteria, case definition: presence of proximal attachment loss $\geq 3 \mathrm{~mm}$ in $\geq 2$ non-adjacent teeth. ${ }^{15}$

- Severity definition: moderate form, sites (PD) $\geq 4 \mathrm{~mm} \leq 6 \mathrm{~mm} \cdot{ }^{16}$
HIV+ patients were recruited from the Orestes Diniz Center between 2007 and 2008. HIV- patients were recruited from the Periodontology Clinic of the School of Dentistry at the Federal University of Minas Gerais (Belo Horizonte, Brazil). All subjects from the HIV- group were sent to the Anonymous Testing Center to confirm negativity for HIV. Those subjects with systemic disease that contraindicated periodontal treatment at that time were excluded.

Only those HIV+ and HIV- subjects with CMP were provided oral hygiene instruction and scaling and root planing prior to surgery. After 45 to 60 days, in cases where patients presented both PD $>5 \mathrm{~mm}$ and also bleeding on probing, a modified Widman surgery was indicated. In the gingivitis group, gingival tissue was removed during extraction, indicated for orthodontic or prosthetic reasons. Later, those subjects with gingivitis received oral hygiene instruction and scaling and root planing, if necessary.

$\mathrm{HIV}+$ data for the sample were obtained from medical records to identify CD4+ and CD8+ T cells and viral load levels (determined no more than 2 months prior to performing the biopsy). The amount of time HAART was used by the patients ranged from 5 to 13 years. No oral disease was observed in any of the cases included.

\section{Immunohistochemistry}

Immunohistochemistry was performed using the streptavidin-biotin standard protocol. Sections of $4 \mu \mathrm{m}$, from routinely processed paraffin embedded blocks, were deparaffinized and dehydrated. Avidin and biotin were blocked. ${ }^{17}$ Slices were not submitted to antigen retrieval. Endogenous peroxidase activity was blocked using $0.3 \%$ hydrogen peroxide. Specimens were incubated with the S-100 primary antibody at a 1:700 dilution (Dako, Carpinteria, USA) for $18 \mathrm{~h}$ at $4^{\circ} \mathrm{C}$. The detection of $\mathrm{S} 100$ was performed with $\mathrm{LSAB}^{\circledR}+$ System-HRP (Dako, Carpinteria, USA) for 30 minutes at room temperature and a solution of 3.3' diaminobenzidine (DAB) (Sigma Chemical, St. Louis, USA) for 3 minutes. After washing with distilled water, the slides were counterstained with Mayer's hematoxylin and mounted 
in Permount (Fisher Scientific, Fair Lawn, USA). Appropriate positive and negative controls were used.

\section{Quantitative and statistical analysis}

Assessment and quantification of immunostain were carried out by a trained investigator (Kap$p a>0.90)$. Counting was carried out with a microscope (Axioskop 2 Plus, Zeiss, Gottingen, Germany) $(\mathrm{x} 400)$ using a meshwork eyepiece $\left(0.1024 \mathrm{~mm}^{2}\right)$. Counting of positive cells was first carried out by field, thereafter by slice, and then the density/LC per $\mathrm{mm}^{2}$ was found.

Additionally, to observe the inflammation intensity, the infiltrate of mononuclear plasma cells and lymphocytes was counted. The infiltrate was classified as mild ( $\mathrm{G} \leq 150$ cells; $\mathrm{CMP} \leq 500$ cells), moderate $(\mathrm{G}>151 \leq 300$ cells; $\mathrm{CMP}>501 \leq 1000$ cells), and intense $(\mathrm{G}>301$ cells; CMP > 1001 cells).

The results were expressed as the average \pm standard deviation (s.d.) of the LC number per $\mathrm{mm}^{2}$. Normal distribution was tested using the ShapiroWilk procedure. Statistical analysis was performed using two-tailed Student's t-test. Correlations were determined by calculating Pearson's correlation coefficients (r). A P value of less than 0.05 was considered statistically significant. The statistical package used was SPSS for Windows 15.0 (IBM Corporation, Chicago, USA).

\section{Results}

Clinically, the groups were homogenous in relation to age and periodontitis severity. Low viral load levels were observed in the HIV+ sample (Table1).

\section{Quantitative analysis of the S100+ cells}

The LC were assessed in four distinct regions and throughout the histological section (Table2). When we compared the regions assessed in HIV+ and HIV- subjects with gingivitis, no statistically significant differences were observed. The same occurred in the comparison of subjects with periodontitis.

No statistically significant difference was observed in the total S100+ LC between HIV+ subjects and HIV- subjects with gingivitis. However, a statistically significant increase in $\mathrm{HIV}_{+}(\mathrm{p}=0.035)$ was observed when compared to HIV- subjects with periodontitis.

The samples were also compared according to infiltrate intensity, and no statistically significant difference was observed between HIV+ and HIV- subjects with the same infiltrate intensity. Additionally, no statistically significant difference was observed when a comparison between samples with mild and intense infiltrate intensity was made. This analysis was carried out to observe possible changes correlated with an increase in inflammation (Table3).

Table 1 - Status samples and periodontal condition.

\begin{tabular}{|c|c|c|c|c|c|}
\hline & & G / HIV- & $\mathrm{G} / \mathrm{HIV}+$ & CMP / HIV- & CMP / HIV+ \\
\hline \multicolumn{2}{|l|}{ Number } & 10 & 10 & 15 & 15 \\
\hline \multicolumn{2}{|l|}{ Age } & $38(34-50)^{*}$ & $38(32-45)^{*}$ & $46(40-60)^{*}$ & $42(32-52)^{*}$ \\
\hline \multirow{2}{*}{ Gender } & Male & 3 & 7 & 7 & 8 \\
\hline & Female & 7 & 3 & 8 & 7 \\
\hline \multicolumn{2}{|c|}{ Blood level CD4 T cells $/ \mathrm{mm}^{3}$} & ND & $521(117-1054)^{*}$ & ND & $450(28-815)^{*}$ \\
\hline \multicolumn{2}{|c|}{ Blood level CD8 T cells $/ \mathrm{mm}^{3}$} & ND & $850(267-1140)^{*}$ & ND & $1048(406-1565)^{*}$ \\
\hline \multicolumn{2}{|c|}{ Viral load } & ND & $20(20-71671)^{*}$ & ND & $20(20-321567)^{*}$ \\
\hline \multicolumn{2}{|c|}{ Gingival Index } & $0.94 \pm 0.91^{\dagger}$ & $1.69 \pm 0.83^{\dagger}$ & $1.05 \pm 0.29+$ & $1.35 \pm 0.65^{\dagger}$ \\
\hline \multicolumn{2}{|c|}{$\%$ sites $\mathrm{PD} \geq 4 \leq 6 \mathrm{~mm}$} & ND & ND & 8.2 & 6.0 \\
\hline \multicolumn{2}{|c|}{$\%$ sites $C A L \geq 3 \mathrm{~mm}$} & ND & ND & 14.9 & 18.6 \\
\hline
\end{tabular}

*: median; ${ }^{\dagger}$ : average and standard deviation; ND: not determined; PD: probing depth; CAL: clinical attachment loss 
Table 2 - Distribution of S100+ LC density according to tissue localization.

\begin{tabular}{c|c|c|c|c|c}
\hline $\begin{array}{c}\text { Periodontal } \\
\text { condition }\end{array}$ & $\begin{array}{c}\text { Pocket epithelium } \\
(\mathrm{PE})\end{array}$ & $\begin{array}{c}\text { Gingival epithelium } \\
(\mathrm{GE})\end{array}$ & $\begin{array}{c}\text { Lamina propria of } \\
\text { the PE }\end{array}$ & $\begin{array}{c}\text { Lamina propria of } \\
\text { the GE }\end{array}$ & Total LC \\
\hline Gingivitis HIV- & $18.53( \pm 22.85)$ & $27.24( \pm 14.16)$ & $18.70( \pm 10.51)$ & $24.57( \pm 11.29)$ & $95.55( \pm 42.08)$ \\
\hline Gingivitis HIV+ & $19.73( \pm 13.70)$ & $38.58( \pm 17.46)$ & $27.93( \pm 17.65)$ & $16.03( \pm 11.01)$ & $107.07( \pm 43.6)$ \\
\hline Periodontitis HIV- & $20.62( \pm 14.30)$ & $40.46( \pm 22.37)$ & $19.75( \pm 17.80)$ & $17.14( \pm 8.04)$ & $99.51( \pm 40.91)^{*}$ \\
\hline Periodontitis HIV+ & $32.07( \pm 29.74)$ & $52.29( \pm 30.41)$ & $33.46( \pm 21.39)$ & $17.68( \pm 10.05)$ & $144.34( \pm 66.88)^{*}$ \\
\hline
\end{tabular}

$* p<0.05$ (Student's $t) ;$ density (cell/ $\left./ \mathrm{mm}^{2}\right)$

Table 3 - Total S100+ LC distribution according to periodontal condition and inflammatory infiltrate intensity.

\begin{tabular}{l|c|r}
\hline \multicolumn{1}{c|}{ Periodontal condition } & $\begin{array}{c}\text { Number of } \\
\text { subjects }\end{array}$ & Total S100+ LC \\
\hline HIV-Mild gingivitis & 2 & $59.02 \pm 54.60$ \\
\hline HIV+ Mild gingivitis & 2 & $138.40 \pm 16.51$ \\
\hline HIV- Moderate gingivitis & 4 & $104.26 \pm 29.34$ \\
\hline HIV+ Moderate gingivitis & 3 & $104.51 \pm 39.26$ \\
\hline HIV- Severe gingivitis & 4 & $105.09 \pm 48.43$ \\
\hline HIV+ Severe gingivitis & 5 & $96.06 \pm 52.91$ \\
\hline HIV- Mild periodontitis & 2 & $59.39 \pm 26.46$ \\
\hline HIV+ Mild periodontitis & 2 & $123.00 \pm 42.77$ \\
\hline HIV- Moderate periodontitis & 4 & $83.94 \pm 22.86$ \\
\hline HIV+ Moderate periodontitis & 7 & $163.51 \pm 81.07$ \\
\hline HIV- Severe periodontitis & 9 & $115.34 \pm 42.88$ \\
\hline HIV+ Severe periodontitis & 6 & $129.08 \pm 57.40$ \\
\hline
\end{tabular}

(Student's t, p > 0.05)

\section{CD4 and CD8 T cells, viral load levels and S100+ LC correlations}

To observe the correlation among S100+ LC density with CD4 and CD8 T-cells, and viral load levels in peripheral blood, the Pearson correlation coefficients were calculated. No statistically significant correlations were observed (Data not shown).

\section{Discussion}

In the present study, the quantitative analysis of total LC revealed a higher count for MCP in HIV+ subjects when compared to HIV- subjects. In the gingivitis samples, no statistically significant difference was observed between HIV+ and HIV- subjects. These results are not in accordance with a previous study ${ }^{9}$ that reported a decrease of LC in AIDS $(\mathrm{HIV}+)$ subjects. However, all HIV+ individuals in the present study were using HAART, with a low viral load, and, consequently, showed less direct aggression by LC. Moreover, both MCP samples were defined by two different criteria, including case definition and severity, ${ }^{18}$ which resulted in homogenous disease severity in HIV+ and HIV- subjects. Thus, this increased LC count in MCP among HIV+ subjects could be associated with the presence of specific pathogens. ${ }^{19-21}$

When we compared samples according to infiltrate intensity, no statistically significant difference was observed between HIV+ and HIV- subjects with the same infiltrate intensity for both gingivitis and periodontitis. Additionally, no statistically significant difference was observed in the LC count with an increase in inflammation, also between $\mathrm{HIV}+$ and HIV- subjects. It is difficult to compare these data to those of previous studies because of different analysis methods, tissue removal techniques, and the antibodies that were used, which might cause divergent results. ${ }^{1,22}$ Moreover, a large number of previous studies compared gingivitis and periodontitis. ${ }^{2,4,6}$ In our understanding, this comparison is not correct because they are distinct periodontal diseases, with different inflammatory cells, cytokines, and pathogens. Moreover, in the majority of previous studies ${ }^{4,23}$, scaling and root planing and oral hygiene instructions were given only to the periodontitis patients, before tissue samples were removed, which would change the number of inflammatory cells. In this study, all inflammatory mononuclear plasma cells and lymphocytes were counted; thus, we can affirm that no changes in LC density were observed to be correlated with increased inflammation, which is in accordance with previous studies. ${ }^{2,6}$ One other study ${ }^{13}$ observed that calculus 
removal, and subsequent decreased inflammation, was responsible for an LC count decrease even in the epithelium and gingival connective tissue. It is important to point out that only this study used the same antibody.

A comparison among the four regions assessed showed no statistically significant differences between HIV+ and HIV- subjects. Another study ${ }^{23}$ observed an increase of LC in the lamina propria and gingival epithelium, comparing gingivitis with periodontitis, in HIV- subjects, thus indicating different characteristics of the immune response between the two diseases. It is also interesting to note that in the pocket epithelium and lamina propria, no changes in LC count were observed. This fact may be related to junctional epithelium permeability, the presence of a local defense through gingival fluid rich in $\operatorname{IgG}$, and the presence of phagocyte cells in the lamina propria infiltrate.

No statistically significant correlation was ob-

\section{References}

1. Cutler CW, Jotwani R. Antigen-presentation and the role of dendritic cells in periodontitis. Periodontol 2000. 2004 Jun;35(1):135-57.

2. Lins RD, Figueiredo CR, Queiroz LM, Silveira EJ, Freitas RA. Immunohistochemical evaluation of the inflammatory response in periodontal disease. Braz Dent J. 2008 Jan;19(1):914.

3. DiFranco CF, Toto PD, Rowden G, Gargiulo AW, Keene JJ, Connelly E. Identification of Langerhans cells in human gingival epithelium. J Periodontol. 1985 Jan;56(1):48-54.

4. Newcomb GM, Seymour GJ, Powell RN. Association between plaque accumulation and Langerhans cell numbers in the oral epithelium of attached gingival. J Clin Periodontol. 1982 Jul; 9(4):297-304.

5. Jotwani R, Cutler CW. Multiple Dendritic cell (DC) subpopulations in human gingival and association of mature DCs with CD4+ T-cells in situ. J Dent Res. 2003 Set; 82(9):736-41.

6. Jotwani R, Palucka AK, Al-Quotub M, Nouri-Shirazi M, Kim $\mathrm{J}$, Bell D et al. Mature dendritc Cells infiltrate the T cell-rich region of oral mucosa in chronic periodontitis: in situ, in vivo and in vitro studies. J Immunol. 2001 Oct;167(8):4693-700.

7. Wood GS, Warner NL, Warnke RA. Leu3/T4 antibodies react with cells of monocyte/macrophage and Langerhans lineage. J Immunol. 1983 Jul;131(1):212-6.

8. Yin MT, Dobkin JF, Grbic JT. Epidemiology, pathogenesis and management of human immunodeficiency virus infec- served between S100+ LC, CD4 T-cells, CD8 Tcells, or viral load. This may also be related to the profile of HIV+ samples, in which all subjects were using HAART with a low viral load and levels of CD4 and CD8 T-cells within the accepted standards.

\section{Conclusions}

The use of HAART can aid in achieving a low viral load and may prevent the destruction of LC in the gingiva of subjects with periodontitis. However, more studies are needed to evaluate changes in the functions of LC in HIV+ subjects with MCP.

\section{Acknowledgments}

This work was supported by grants from the Minas Gerais State Research Foundation (FAPEMIG) and the National Council for Scientific and Technological Research (CNPQ, \# 301490/2007-4).

tion in patients with periodontal disease. Periodontol 2000. 2007 Jan; 44(1):55-81.

9. Myint M, Yuan ZN, Schenck K. Reduced numbers of Langerhans cells and increased HLA-DR expression in Keratinocytes in the oral gingival epithelium of HIV-infected patients with periodontitis. J Clin Periodontol. 2000 Jul; 27(7):513-519.

10. Pimpinelli N, Riccardi R, Piluso S, Mori M, Ficarra G, Romagnoli P. Immune cell infiltration in periodontal lesions of HIV infected subjects. Antigenic and ultra-structural features. Eur J Dermatol. 1995 May; 5(7):607-13.

11. Hofer D, Hämmerle CH, Grassi M Lang NP. Long-term results of supportive periodontal therapy in HIV-seropositive and HIV-seronegative patients. J Clin Periodontol. 2002 Jul;29(7):630-37.

12. Gonçalves LS, Ferreira SMS, Silva Jr. A, Villoria GE, Costinha LH, Colombo AP. Association of T CD4+ limphocyte levels and chronic periodontitis in HIV-infected Brazilian patients undergoing highly active anti-retroviral therapy: Clinical results. J Periodontol. 2005 Jun;76(6):915-22.

13. Dereka XE, Tosios KI, Chrysomali E. Factor XIIIa+ dendritic cells and S-100 protein+ Langerhans Cells in adult periodontitis. J Periodontol Res. 2004 Dec;39(6):447-52.

14. Lopez NJ, Da Silva I, Ipinza J, Gutierrez J. Periodontal therapy reduces the rate of preterm low birth weight in women with pregnancy-associated gingivitis. J Periodontol. 2005 Nov;76(11 suppl):2144-53. 
15. Tonetti MS, Claffey N. Advances in the progression of periodontitis and proposal of definitions of a periodontitis case and disease progression for use in risk factor research. Group C consensus report of the 5th European Workshop in Periodontology. J Clin Periodontol. 2005 Jun;(6 suppl):210-3.

16. American Academy of Periodontology. Parameter on chronic periodontitis with slight to moderate loss of periodontal support. J Periodontol. 2000 May;71(5 suppl):856-8.

17. Miller KT, Kubier PH, Reynolds BH. Blocking on endogenous avidin-biotinactivity in immunohistochemistry: The use of skim milk as an economical and effective substitute for commercial biotin solutions. Appl Immunohistochem Mol Morphol. 1999 Jan;7(1):63-5.

18. Costa FO, Guimarães AN, Segundo TK, Cota LOM, Pataro AL, Cortelli SC, et al. Impact of different periodontitis case definitions on periodontal research. J Oral Sci. 2009 Jun;51(2):199-206.

19. Odden K., Schenck K., Hurlen B. High numbers of T cells in gingival from patients with human immunodeficiency virus (HIV) infection. J Oral Pathol Med. 1995 Oct;24(9):413-9.
20. Myint M, Odden K, Schreurs O, Halstensen TS, Schenck $\mathrm{K}$. The gingival plasma cell infiltrate in HIV-positive patients with periodontitis is disorganized. J Clin Periodontol. 1999 Jun;26(6):358-365.

21. Gonçalves LS, Ferreira SMS, Souza CO,Souto R, Colombo AP. Clinical and microviological profiles of human immunodeficiency vírus (HIV)-seropositive brazilians undergoing highly active antiretroviral therapy and HIV-seronegative brazilians with chronic periodontitis. J Periodontol. 2007Jan;78(1):8796.

22. Saglie FR, Pertuiset JH, Smith CT, Nestor MG, Carranza FA, Newman MG, et al. The presence of bacteria in oral epithelium in periodontal disease. III. Correlation with Langerhans cells. J Periodontol. 1987 Jun;58(6):417-22.

23. Cury PR, Furuse C, Rodrigues AEA, Barbuto JA, Araujo VC, Araújo NS. Interstitial and Langerhans' dendritc cells in chronic periodontitis and gingivitis. Braz Oral Res. 2008 JulSep;22(3):258-63. 